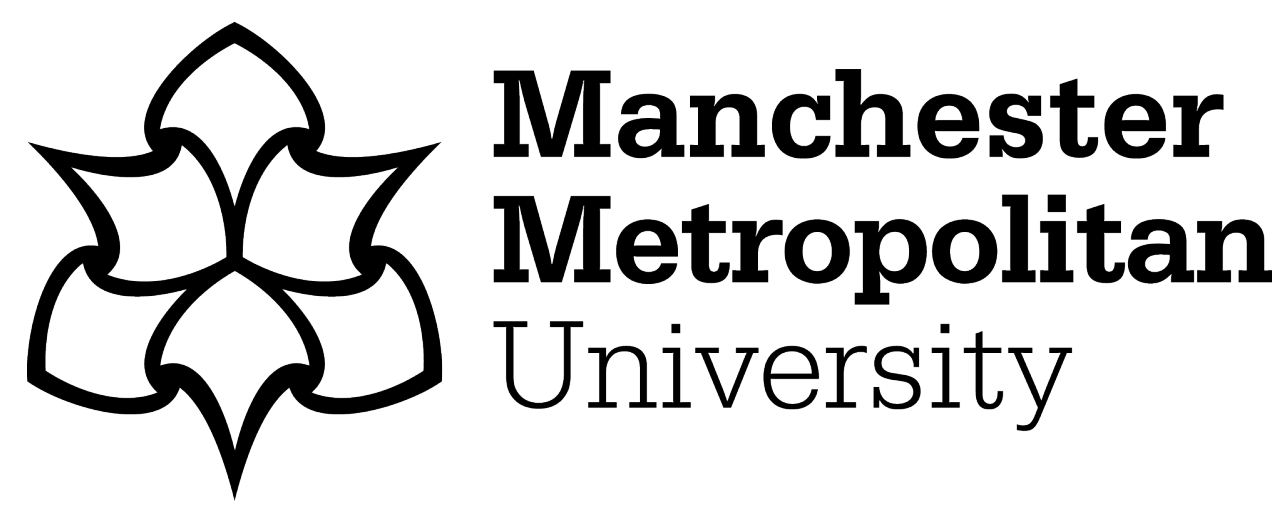

Heyes, Kim ORCID logoORCID: https://orcid.org/0000-0002-9029-545X (2016) Using virtual ethnography to research vulnerable participants online: a case study of mental health online community support forums. In: SAGE Research Methods Cases Part 2. SAGE Research Methods. SAGE Publications Ltd.. ISBN 9781526403605

Downloaded from: https://e-space.mmu.ac.uk/617506/

Version: Published Version

Publisher: SAGE Publications Ltd.

DOI: https://doi.org/10.4135/9781526403605

Please cite the published version 


\section{@SAGE researchmethods \\ cases}

\section{Using Virtual Ethnography to Research Vulnerable Participants Online: A Case Study of Mental Health Online Community Support Forums}

Contributors: Kim Heyes

Pub. Date: 2016

Access Date: January 27, 2017

Academic Level: Postgraduate

Publishing Company: SAGE Publications Ltd

City: London

Online ISBN: 9781526403605

DOI: http://dx.doi.org/10.4135/9781526403605

C2017 SAGE Publications Ltd. All Rights Reserved.

This PDF has been generated from SAGE Research Methods Cases. 


\begin{abstract}
Researching vulnerable groups has long been a subject of academic work and has been subject to rigorous ethical approvals for conducting face-to-face interviews. With new technologies come new challenges. Groups of people come together on online forums and have anonymous discussions about anything and everything; this often includes the source of their vulnerabilities. In the discussed research, the focus of these community support forums is mental health. It is difficult to shift the focus of researching vulnerable adults away from face-toface to online, particularly as there are no physical cues to give meaning to the language used. The value therefore must be contained in the written word, and there are "unique characteristics" in the data due to this. There is something quite refreshing about focusing on the text rather than body language, and there are many suggestions on how to conduct this type of research. My research focuses on using virtual ethnography of online focus groups, which has been fraught with issues, but has proved a useful learning experience.
\end{abstract}

Learning Outcomes

By the end of this case, students should be able to

- Recognize the limitations within their own research design and be able to defend their use of a particular methodology

- Critically evaluate the use of virtual ethnography

- Understand how virtual ethnography can inform the study of qualitative data sets from online environments

\title{
Project Overview and Context
}

There is an increasing amount of research focusing on online communities, and although there appears to be a plethora of research into support forums for users with health issues, there is a gap in the research market when it comes to specialist community support forums (SalzmannErikson and Eriksson, 2012). Online community forums for people with mental health issues are plentiful, and they are also incredibly accessible, particularly if you use open-access forums such as Reddit. Gatekeepers such as forum moderators control most of the closed access sites (where you must sign up and log in using a password each time), and some request that you fill out lengthy forms, proving who you are and what your intentions are, along with a copy of your ethical approval. This is cumbersome; however, once you have gone through this process, the gatekeepers can be very helpful. Extra time should be factored in for this process, and you are generally only able to complete this if ethical approval has already been granted (Witney, Hendricks, \& Cope, 2016). 
Ethical perspectives may differ at this point. Some believe that everything online is in the public domain, and if you do not need log in details, then the information is eligible for research without seeking consent from the person who posted the words. Salzmann-Erikson and Eriksson's (2012) study used archival data from an online forum, arguing that the research was not considered to be on human participants (as it was from the past), and is in the public domain, so it does not need consent. However, there are many researchers who disagree with this perspective (Flicker, Haans, \& Skinner, 2004; Hudson \& Bruckman, 2004). Even once access was granted, I started my questions with who I was and what I was going to do with the responses. This gives the users the option of participating or not and helps to build trust between participant and researcher (Im, Chee, Tsai, Bender, \& Lim, 2007; Ridings, Gefen, \& Arinze, 2002).

\section{Participant Consent}

Perfectly worded consent forms are difficult to use when capturing data online. Once a participant has seen the information and answered the question, they rarely return a consent form. I found that the most effective method was to state in the forum post who I was, what I was doing, for whom or what, and what will happen to their words (Kozinets, 2010; Witney et al., 2016). It is no longer realistic to expect virtual participants who are already anonymized to read through consent forms, sign them, and send them to another email address, when all that could be dealt within a few lines. A full disclosure within the initial post means that the participants are aware that by responding, they are giving consent. The issue with this is around withdrawal of consent, and for this, I would advise you speak to your individual ethics board. I posted that they could email me or my supervisor if they wished to withdraw, but your ethics board may require something else. Also speak to other researchers, they may have already encountered these issues and will have pearls of wisdom that they are happy to share with you.

\section{Creating Research Space}

One of the mistakes that I made was thinking naively that if I created the research space, the participants would come. A year beforehand, I had created a Facebook group called Community Mental Health Support Groups, with the premise that I was preparing the participants for the upcoming research. I then created a forum (from a free online forum site) and created instruction threads that were "sticky," which included the participant consent form, information about me, and where to find help if they should find participating in my forum upsetting. Then my five carefully thought-through research questions were posed-one per 
thread. They were "locked" so that people could comment (and hopefully continue to have a conversation with each other), but could not create their own thread. I have purposely decided not to put my questions in this case study as the focus is on methodology; however, please email me if you would like a copy of these. I advertised this forum through my Facebook page and also my personal page. Unfortunately, for quite some time, the only people who signed up "anonymously" to my forum were my friends and family. Others, when posting an answer to a question such as "what are the benefits of using a mental health forum," posted, "I've never used one." In all, 40 people had to be discounted from my research. Setting up a forum takes time, patience, and more hours in the day than one may realize.

\section{Virtual Ethnography: Method in Action}

Virtual ethnography is a relatively new concept of methodology, and many researchers have found that online communities replicate those of offline communities (King \& Moreggi, 1998; Tate \& Zabinski, 2004; Yalom \& Leszcz, 2005), hence the use of a method (ethnography) that is usually only conducted on a face-to-face basis.

Despite there being a paucity of research that commends the use of ethnographic methods for virtual spaces, there is also much to critique its use, and no one method within virtual ethnography has emerged as preferential (Bengry-Howell, Wiles, Nind, \& Crow, 2011). My research questions demanded something a little more detailed than questionnaire responses, and I was interested in the use of the online forums specifically, so it seemed fitting to keep it within that environment and explore through the use of virtual ethnography.

My original plan of creating a community on a Facebook page and maneuvering it to my forum had not been as fruitful as anticipated, and it was difficult to then become part of other online communities to be true to the ethnographic research. To immerse oneself in a community takes time, and I did not feel as though I had enough time to become part of the community in the second and third support forums before the research began. Thus, to a certain extent, the understanding of the relationships of the participants and the community came after the research questions had been asked. In retrospect, I do not think that this detracted from the research, and I was still able to participate in the forums and facilitated conversation between the participants.

One model of virtual ethnography that has been utilized a great deal by researchers is netnography (Kozinets, 2010). This type of research is a fusion of online and offline research, used to build up a holistic portrait of the users. The SAGE publication "Netnography: doing ethnographic research online" (Kozinets, 2010) is an incredibly useful resource if you are 
looking to conduct netnographic research. I chose not to define my method as netnography, although it was heavily influenced by the ideologies of Kozinets (2010). Virtual ethnography is a slightly more flexible term and one that I feel fits my research methodology as it is concentrating on online interactions alone.

From very early Internet use, academics have claimed that the nature of interactions in online virtual communities were ripe for ethnographic research (Rheingold, 1993). There have been a variety of methods used to observe these communities since the early 1990s; however, the method I initially chose was a mixture of Hauben and Hauben's (1996) study, where a bulletin board method is hosted on a web forum, and Baym's (1995) approach of evolving questions over time.

Hauben and Hauben (1996) observed online participants on a hobbyist site Usenet. They termed the users "Netizens" and became part of the group discussions. The participation of the researchers was seen as a facilitation of conversation about their research, and consequently, the research was rich with data (Hauben \& Hauben, 1996). Over time, the names for areas on the Internet have changed somewhat, sites such as Hauben and Hauben's are now called forums, and the bulletin boards are now threads. To replicate this type of environment, I created my own forum that was of a similar layout to the types of forum the targeted groups already used. This was to ensure that the forum was not linked to any already established forum which may have discouraged potential participants. An easy-to-use site from freeforums.net was selected; this was due to it being free to access for the researcher, easy to set up, and simple for the participants to navigate.

The questions were open questions, designed to elicit response and discussion between forum members. The participants could answer just one question or all five if they so wished. The forum remained open so that they could sign in to see the answers that other participants had given and comment on these if wanted. The participants knew that they were participating in research before they signed up to the forum, and most answered all of the questions; however, they did not then log back in or use it as a discussion platform.

The idea that replicating the style of a forum would make participants feel comfortable was somewhat naïve. Business and marketing sectors have researched what makes a good community forum for many years and found that those forums that offer something in return for participation are the most likely to recruit participants. However, loyalty to particular items (products such as a particular brand of coffee, for example) would encourage the participants to be part of the forum long term (McWilliam, 2000). The forum I set up offered little in the way of incentive. Other mental health support forums offered advice on particular mental health 
issues or links to other websites with helpful information. The option for participants to ask their own questions and start threads also serves as an incentive that my forum was unable to provide.

As previously stated, the data collected from this forum were mostly unusable, and this is where I had to change my methodology somewhat-although it was half-way through my research. Hine (2008) stated that ethnographic researchers should not expect to become an accepted member of the group (unlike Baym, 1995; Hauben \& Hauben, 1996), as their role is to be that of a "tolerated and accepted observer" (p. 10). This was the method of virtual ethnography I then applied to Reddit and an existing mental health support forum.

Chandler (2014) found that she had success conducting her research through Reddit, despite not having the levels of loyalty described as necessary by McWilliam (2000). I therefore decided to post about my research on the mental health forum of Reddit and asked the original five questions. Once again, the responses were not great and discussion was not forthcoming. By rewriting one of the questions to illicit a more emotive response, (asking about the negative experiences) many more users commented. This was posted in two areas of the mental health forum, "depression" and "general anxiety," yet only one gained any responses at all. The questions were carefully worded to ensure that the participants were fully aware that their responses would be used for research purposes (Vayreda \& Antaki, 2009). This meant that many people were reluctant to respond, which made it difficult to collect the data once again. There are many different methods that my fellow researchers have employed to get round this, such as not stating that they are a PhD student, but my ethical approval was granted on the understanding that I told my participants clearly who I was and where I was from.

Lived experience of the topic in question is also helpful if you are trying to recruit participants. Few people responded to my post until I stated that I had a mental health issue. If you tell them your personal reason for the research (as well as the fact that it is for your qualification), you could potentially get more respondents. Obviously, this is dependent upon the nature of your project and an understanding that this type of disclosure can be problematic (Finlay, 2002).

The most fruitful forum was an established mental health community support forum, although navigating access to this was a lengthy process. It was a lesson learnt for future research projects in this area. I used the same approach as in the Reddit forum, I posted all five questions, and then I posted an individual question designed to elicit a more emotive response. Once again, this became the most popular post, and I was able to gain some usable data.

Another ethical issue was that I had access to a lot of information that my participants had 
posted in other forum areas, such as age and gender. However, ethically I did not feel that this was an appropriate way to collect data for this project and ignored any links from the participants through to other forum threads. It was difficult to ignore all of the other data that could have helped me to build a holistic profile of the participants, and I could understand the temptation of other researchers to utilize such rich pickings! Salzmann-Erikson and Eriksson (2012) were able to justify their method, as to ask for participants may have greatly skewed their data. Personal ethics plays a large part in researching online data, and it may be worth spending some time thinking about your own stance and reasons for using certain data sets, before starting your research.

Interestingly, the study showed that people are reticent to answer pre-set questions in the online format, but would rather tell me their stories face-to-face, despite being able to share vast amounts of information online. Many people contacted me through the use of private messaging to ask whether they could talk to me and ask for advice on their situations. In line with my ethical considerations, I was unable to offer any advice but was able to signpost them, and I did not use any of that information in my research. Perhaps netnography, therefore, was the most appropriate form for my research, and I should have considered this as an option from the start, although I think that using both online and face-to-face research would have detracted from my analysis of the words used just online.

\section{Further Considerations}

Another issue encountered was due to the lack of a fully representative participant sample. There is an assumption that everyone accesses information provided on the Internet; however, with almost $60 \%$ of the world's population still without access to the Internet, this assumption can leave vulnerable people without the help they need (Internet live stats, 2016). Even if they do have access to the Internet, it is plausible to expect that some will not be able to use it sufficiently. The amount of information about mental ill health available online can be valuable to people, especially as cuts to funding look set to continue despite numbers of people diagnosed with mental health conditions rising (Twenge, 2015). Huge waiting lists for counselors and specialists may force people to seek alternatives, and those with access to online services may find their consumer prowess is vital in receiving alternative care (NHS Choices Online, 2015). However, more research into the effectiveness of this is necessary and will be a continual process over the coming years as the nature of the consumer changes.

Generally, it cannot be assumed that because the individuals have access to the Internet they will wish to utilize this as their main method of treatment. Some people will continue to use face-to-face methods as their preference, or they may decide to not get any treatment at all, 
which may be to the detriment of the individual.

\section{Conclusion}

The participants were eventually recruited through three different forums. It proved difficult to recruit participants through initial methods. The Facebook page proved fruitful; however, it mainly yielded participants from my friends and family. This meant that there were some people signed up to the forum for whom the data were invalid. Other participants were not able to be used within the research as they gave other information that was not appropriate to the research.

As you can see, using ethnographic methods to research online forums is fraught with issues. Do you immerse yourself fully as per Baym (1995) and Hauben and Hauben (1997) which is time-consuming for post-graduate research but gives you a satisfactory ethnographic profile, or do you become a visitor to the site, as Hine (2008) suggests, effectively questioning the participants and probing them for further responses as an "outsider"? Both have their benefits and their drawbacks, but l've yet to find conclusive evidence that either is the best way. Your research can benefit understanding as long as you can actively defend your reasoning for using the method. I failed to fully engage with virtual ethnography in the way I wanted, by setting up and running my own forum, so ultimately I ended up with a slightly piecemeal way of conducting my virtual ethnography. I stand by my reasoning for conducting the research purely online, without any face-to-face or personal contact from the participants, and the analysis yielded some interesting results that will be continued in future research. Despite the best of intentions, even the most robust research methodology can go awry-my advice is to go with it and see where it takes you!

\section{Exercises and Discussion Questions}

1.Is it ethical to use data from a participant that you recognize, even if all participants are supposed to be anonymous?

2.There are many ethical concerns around using online data; what kinds of issues do you think are the most important to consider when researching vulnerable groups found online?

3.What are the drawbacks of using virtual ethnography in this kind of study?

4.Can you think of another method that would appropriately gather the data in this study?

5.Are online data as valuable as face-to-face data? Discuss both sides of the argument.

\section{Further Reading}

Fielding, N. G., Lee, R. M., \& Blank, G. (2008). The SAGE handbook of online research 
methods. London, England: SAGE.

Kozinets, R.V. (2010). Netnography: Doing ethnographic research online. Thousand Oaks, CA: SAGE.

Web Resources

Bengry-Howell, A., Wiles, R., Nind, M., \& Crow, G. (2011). Methodological innovation in the social sciences (case studies). Re trie ved from http://eprints.ncrm.ac.uk/1844/1/Review_of_methodological_innovations.pdf (accessed 15 July 2016).

\section{References}

Baym, N. (1995). The emergence of community in computer-mediated communication. In S. Jones (Ed.), Cybersociety (pp. 138-167). Thousand Oaks, CA: SAGE.

Bengry-Howell, A., Wiles, R., Nind, M. \& Crow, G. (2011). Methodological innovation in the social sciences (case studies). Re trie ved from http://eprints.ncrm.ac.uk/1844/1/Review_of_methodological_innovations.pdf (accessed 15 July 2016).

Chandler, A. (2014). A sign that something is wrong? Young people talking about self-harm. $\begin{array}{lllllllllllllll}R & e & t & r & i & e & v & e & d & f & r & 0 & m\end{array}$ https://www.era.lib.ed.ac.uk/bitstream/handle/1842/10422/SASHwebbriefing.pdf? sequence=1\&isAllowed=y (accessed 15 July 2016).

Finlay, L. (2002). "Outing" the researcher: The provenance, process, and practice of reflexivity. Qualitative Health Research, 12, 531-545.

Flicker, S., Haans, D., \& Skinner, H. (2004). Ethical dilemmas in research on Internet communities. Qualitative Health Research, 14, 124-134.

Hauben, M., \& Hauben, R. (1996). Netizens: On the history and impact of Usenet and the Internet. Los Alamitos, CA: IEEE Computer Press.

Hine, C. (2008). Virtual ethnography: Modes, varieties and affordances. In N. G. Fielding, R. M. Lee, G. \& Blank (Eds.), The SAGE handbook of online research methods (pp. 257-270). London, England: SAGE.

Hudson, J. M., \& Bruckman, A. (2004). "Go Away": Participant objections to being studied and the ethics of chatroom research. The Information Society, 20, 127-139.

Im, E., Chee, W., Tsai, H., Bender, M., \& Lim, H. J. (2007). Internet communities for 
recruitment of cancer patients into an internet survey: A discussion paper. International Journal of Nursing Studies, 44, 1261-1269.

Internet Live Stats. (2014, September 16). Number of Internet users (2016). Retrieved from http://www.internetlivestats.com/internet-users (accessed 4 August 2016).

King, S. A., \& Moreggi, D. (1998). Internet therapy and self-help groups-the pros and cons. In J. Gackenbach (Ed.), Psychology and the Internet: Intrapersonal, interpersonal, and transpersonal implications (pp. 77-109). San Diego, CA: Academic Press.

Kozinets, R. V. (2002). The field behind the screen: Using netnography for marketing research in online communities. Journal of Marketing Research, 39, 61-72.

Kozinets, R. V. (2010). Netnography: Doing ethnographic research online. Thousand Oaks, CA: SAGE.

McWilliam, G. (2000). Building stronger brands through online communities. Sloan Management Review, 41(3).

Munro, E. R., Holmes, L., \& Ward, H. (2005). Researching vulnerable groups: Ethical issues and the effective conduct of research in local authorities. British Journal of Social Work, 35 , 1023-1038.

NHS Choices Online. (2015). Online mental health services. Retrieved from http://www.nhs.uk/conditions/online-mental-health-services/pages/introduction.aspx (accessed 5 August 2016).

Rheingold, H. (1994). The virtual community: Finding connection in a computerized world. London, England: Secker \& Warburg.

Ridings, C. M., Gefen, D., \& Arinze, B. (2002). Some antecedents and effects of trust in virtual communities. Journal of Strategic Information Systems, 11, 271-295.

Salzmann-Erikson, M., \& Eriksson, H. (2012). LiLEDDA: A six-step forum-based netnographic research method for nursing science. Aporia, 4, 6-18.

Tate, D.F., \& Zabinski, M.F. (2004). Computer and Internet applications for psychological treatment: Update for clinicians. Journal of Clinical Psychology, 60, 209-220.

Twenge, J. M. (2015). Are mental health issues on the rise? Psychology Today. Retrieved from https://www.psychologytoday.com/blog/our-changing-culture/201510/are-mental-health-issuesthe-rise (accessed 5 August 2016).

Vayreda, A., \& Antaki, C. (2009). Social support and unsolicited advice in an online bipolar 
disorder forum. Qualitative Health Research, 19, 931-942.

Witney, C., Hendricks, J., \& Cope, V. (2016). Variation of Kozinets' framework and application to nursing research. Nurse Researcher, 23, 36-41.

Yalom, I., \& Leszcz, M. (2005). Theory and practice of group psychotherapy (5th ed.). New York, NY: Basic Books. 